Pesq. Vet. Bras. 37(10):1079-1084, outubro 2017 DOI: 10.1590/S0100-736X2017001000007

\title{
Timpanismo gastrointestinal em equídeos alimentados com Panicum maximum com alto conteúdo de amido $^{1}$
}

\begin{abstract}
Taciane M. Souza ${ }^{2}$, Thiago V. Lopes ${ }^{3}$, Henry Wajnsztejn ${ }^{4}$, Raul D. Pazdiora ${ }^{5}$, Franklin Riet-Correa ${ }^{6,7}$, Rodrigo I. Fujihara ${ }^{2}$, Igor M. Mansur ${ }^{5}$ e Sandro V. Schons ${ }^{5 *}$

ABSTRACT.- Souza T.M., Lopes T.V., Wajnsztejn H., Pazdiora R.D., Riet-Correa F., Fujihara R.I., Mansur I.M. \& Schons S.V. 2017. [Intestinal bloat in equids fed with Panicum maximum of high starch content.] Timpanismo gastrointestinal em equídeos alimentados com $\mathrm{Pa}$ nicum maximum com alto conteúdo de amido. Pesquisa Veterinária Brasileira 37(10):10791084. Universidade Federal de Rondônia, Av. Norte-Sul 7300, Bairro Nova Morada, Rolim de Moura, R0 76940-000, Brazil. E-mail: sandroschons@hotmail.com

Acute intestinal bloat occurs in horses and mules introduced into sprouting Panicum maximum cv. Tanzania, cv. Massai and cv. Mombaça pastures in northern Brazil during the rainy season. It has been suggested that the disease is due to high concentrations of non-structural carbohydrates in this grass. The paper aimed to study outbreaks of colics in the state of Rondônia, Brazil and contribute to the knowledge of the carbohydrates contained in P. maximum as the cause of the disease. For this, ten farms which had cases of intestinal bloat were visited. On two farms, horses were introduced into such a toxic pasture. Samples of pasture were collected for determination of digestible energy, lysine, dry matter, water soluble carbohydrates, ether soluble carbohydrates, non-fiber carbohydrates, neutral detergent fiber, acid detergent fiber, lignin, starch, and fat. Samples of P. maximum pastures from neighboring farms, where the disease was not occurring, and from Cynodon dactylon pastures where the horses had been grazing before were also collected. The results showed that colics occur in the rainy season in sprouting pasture with a morbidity of $31.6 \%$, and lethality of $86.1 \%$. The pastures which induce colic showed significantly $(\mathrm{P}=0.0072)$ higher starch concentration $(8,3$ and $9,2 \%)$ than pastures of $P$. maximum which did not cause colic $(0,9$ and $4,3 \%)$ as well as the Cynodon dactylon pastures ingested previously by the horses $(0.2$ and $0.8 \%$. On another farm, the disease was produced experimentally in a horse receiving in the feeder P. maximum collected from a toxic pasture with $6.5 \%$ of starch. The same pasture did not cause colic from November to February with starch content of 2.7 to $5.1 \%$. It is suggested that the cause of colic in equids ingesting sprouting pasture of $P$. maximum is the high starch content of this pasture during the groth period.
\end{abstract}

INDEX TERMS: Bloat, carbohydrates, equids, starch, Panicum maximum.

RESUMO.- Timpanismo intestinal agudo em cavalos e mulas introduzidos em pastagens de Panicum maximum cv. Tanzânia, cv. Massai e cv. Mombaça são relatados na

\footnotetext{
${ }^{1}$ Recebido em 2 dezembro de 2015.

Aceito para publicação em 12 de fevereiro de 2017.

${ }^{2}$ Pós-Graduação em Ciências Ambientais, Universidade Federal de Rondônia (UNIR), Av. Norte-Sul 7300, Bairro Nova Morada, Rolim de Moura, R0 76940-000, Brasil.

${ }^{3}$ Pós-Graduação em Medicina Veterinária, Universidade Federal do Acre (UFAC), Rodovia BR-364 Km $4 \mathrm{~s} / \mathrm{n}$, Distrito Industrial, Rio Branco, AC 69920-900, Brasil.

${ }^{4}$ Medicina Veterinária, Centro Universitário Luterano de Ji-Paraná, Av.
}

região norte do Brasil, durante o período das chuvas. As causas são desconhecidas, porém, tem sido sugerido que estão associados a um maior armazenamento de carboi-

Eng. Manfredo Barata Almeida da Fonseca 762, Jardim Aurelio Bernardi, Ji-Paraná, RO 76907-438, Brasil.

${ }^{5}$ Laboratório de Histopatológica, UNIR, Av. Norte-Sul 7300, Bairro Nova Morada, Rolim de Moura, R0 76940-000, Brasil. *Autor para correspondência: sandroschons@unri.br

${ }^{6}$ Hospital Veterinário, Centro de Saúde e Tecnologia Rural, Universidade Federal de Campina Grande (UFCG), Av. Universitária s/n, Patos, PB 58708-110, Brasil. E-mail: franklin.riet@pq.cnpq.br

${ }^{7}$ National Institute of Agriculture Research (INIA), La Estanzuela, CP 40.000, Colonia, Uruguay. 
dratos não fibrosos na gramínea. Este trabalho teve por objetivos realizar um levantamento epidemiológico dos surtos de cólicas ocorridos no Estado de Rondônia, assim como contribuir com o estudo da ação dos carboidratos de $P$. maximum na ocorrência da doença. Para isso foram realizadas visitas em 10 propriedades que apresentaram casos da enfermidade. Em duas propriedades foram introduzidos equinos no mês de março e foram coletadas amostras de pastagens para a determinação de energia digestiva, lisina, matéria seca, carboidratos solúveis em água, carboidratos solúveis em éter, carboidratos não fibrosos, fibra de detergente neutra, fibra de detergente ácido, lignina, amido, gordura e proteína bruta. Essas determinações foram realizadas, também, em amostras de pastagens de $P$. maximum de outras propriedades onde não estavam ocorrendo cólicas e das pastagens de Cynodon dactylon de onde provinham os equinos. Os resultados mostraram que os surtos de cólica ocorrem na época de chuva, quando as pastagens estão rebrotando com uma morbidade de $31,6 \%$, e letalidade de $86,1 \%$. As análises bromatológicas mostraram uma diferença significativa nas concentrações de amido $(\mathrm{P}=0,0072)$ do $P$. maximum que causou cólica ( $8,3 \%$ e 9,2\%), quando comparado com o P. maximum das outras propriedades $(0,9 \%$ e $4,3 \%)$ e com o Tifton, utilizado previamente na alimentação dos mesmos equinos $(0,2 \%$ e $0,8 \%)$. Em outra fazenda a doença foi reproduzida experimentalmente em um equino, no mês de março administrando P. maximum cortado contendo $6,5 \%$ de amido. A mesma pastagem não causou cólica quando foi administrada a equinos entre os meses de novembro a fevereiro, com $2,7 \%$ a $5,1 \%$ de amido. Estes resultados sugerem que a causa das cólicas em equídeos em pastagens de $P$. maximum, na época de rebrote, é o alto conteúdo de amido das mesmas.

TERMOS DE INDEXAÇÃO: Amido, carboidratos, cólica, equídeos, Panicum maximum.

\section{INTRODUÇÃO}

Atualmente, o território brasileiro possui uma área de pastagens destinada à produção de ruminantes e herbívoros, com aproximadamente 180 milhões de hectares, sendo que $12 \%$ é cultivada com Panicum maximum (Martha Jr \& Corsi 2001, Mari 2003, Macedo 2005). Esta espécie é originária da África tropical e foi introduzida no Brasil pela Embrapa, durante os anos de 1990. Após a sua implantação sempre esteve em destaque pela alta produtividade, boa qualidade nutricional e fácil adaptação em várias regiões do país, em especial em áreas desmatadas utilizadas para pecuária, como as da região Norte. Além disso, é uma forrageira com bons resultados produtivos em outras categorias animais, como equinos e ovinos, ao contrário de Braquiaria spp., que são pouco consumidas por estas espécies (Jank 2003). No entanto, desde a época da introdução da forrageira na região Norte nos anos 90, a mesma vem causando problemas de cólicas em equídeos, durante o período das chuvas. Os casos de cólica já foram relatados no Pará, Rondônia e Acre (Cerqueira et al. 2009, Schons et al. 2012). Recentemente foram diagnosticados casos de dilatação de ceco em bovinos alimentados com Panicum maximum cultivar (cv.) Mombaça e cv. Tanzânia, fertilizadas com ureia e cama de frango, em sistema de pastejo rotativo (Riet-Correa et al. 2011). A etiologia da doença em equinos e bovinos ainda é desconhecida, embora tenham sido sugeridas prováveis causas, como a intoxicação por saponinas contidas na planta, intoxicação por esporidesmina produzida por Pithomyces chartarun e intoxicação por cantaridina produzida por Epicautas spp. No entanto, não foram encontrados indícios nas pastagens que comprovem tais causas (Cerqueira et al. 2009); porém, os valores de carboidrato não fibrosos (CNF) encontrados no $P$. maximum nos experimentos em equinos apresentavam o dobro do valor da média da gramínea no país, sugerindo que as cólicas causadas por $P$. maximum na região Amazônica poderiam estar ligadas a altas concentrações de carboidratos rapidamente fermentáveis (Cerqueira 2010). Possivelmente a toxicidade do P. maximum para os equinos seja devido aos mesmos fatores que causam toxicidade em bovinos, que também apresentam como sinal clínico primário o timpanismo intestina.

Este trabalho teve por objetivo estudar os surtos de cólicas em equinos pastejando em P. maximum na Amazônia ocidental, bem como, contribuir com o conhecimento da ação dos carboidratos não estruturais na etiopatogenia do timpanismo intestinal causado por essa gramínea.

\section{MATERIAL E MÉTODOS}

Levantamento epidemiológico dos casos de cólica em equídeos na microrregião da Amazônia Ocidental. A partir da ocorrência de casos de cólica em cavalos e mulas, alimentados com Panicum maximum, foram realizadas visitas em 10 propriedades rurais, localizadas nos municípios de Ji-Paraná, Cacoal, Presidente Médici, Nova União e Ouro Preto do Oeste, durante o período de 2012 a 2014. Durante as visitas foram observados as pastagens e o tempo de plantio, o manejo dos equinos, a utilização de concentrado, o tempo de permanência dos animais na pastagem, o curso clínico, o tratamento utilizado e a recuperação dos animais enfermos. Quando possível se realizou o exame clínico dos animais intoxicados. A necropsia foi realizada em seis equinos intoxicados, provenientes de quatro diferentes propriedades. Amostras de fezes dos animais necropsiados foram colhidas diretamente da ampola retal, e encaminhadas ao laboratório de parasitologia para contagem de ovos nas fezes (OPG) utilizando a técnica de Gordon e Whitlock.

Para verificar a relação dos casos de cólica equina com o clima amazônico foram coletados os dados climáticos de precipitação e temperatura, durante os anos em estudo, na Estação Meteorológica do município de Cacoal - A939, (latitude $11.445837^{\circ}$ longitude $61.434146^{\circ}$ e altitude de $\left.184 \mathrm{~m}\right)$.

Análise bromatológica de pastagens de Panicum Maximum cv. Tanzânia e cv. Massai e alterações clínicas de equinos introduzidos nas mesmas. A toxicidade dos cv. Tanzânia e Massai e o quadro clínico da intoxicação foi estudado, durante o mês de março, em duas propriedades com histórico de cólica em equinos, na microrregião da Amazônia ocidental. Em uma das propriedades foram introduzidos dois equinos em uma pastagem de $P$. maximum cv. Massai e na outra, cinco equinos no P. maximum cv. Tanzânia. Os equinos foram monitorados durante o período de permanência nas pastagens. Quando confirmado o quadro clíni- 
co da intoxicação os animais eram submetidos à exame clínico e retirados da gramínea para tratamento. Foi realizado, também, determinação de OPG nas fezes.

No exame clínico eram avaliadas as frequências cardíaca e respiratória, os movimentos cecais, a temperatura retal, a distensão abdominal e o tempo de preenchimento capilar. Foram coletas amostras da pastagem no momento da entrada dos animais, bem como de Panicum maximum var. Tanzânia de propriedades vizinhas, sem histórico de cólica em equinos. As amostras foram colhidas no período da tarde, com auxílio de um quadrado de madeira com diâmetro de $1 \mathrm{~m}^{2}$, lançado em 10 pontos aleatórios da pastagem. A forragem presente no interior do quadro foi cortada e pesada e uma subunidade foi enviada ao laboratório de Equi-Analytical- Laboratories (730 Warren Road, Ithaca, NY 14850, USA) para determinar a energia digestiva, lisina, matéria seca, carboidratos solúveis em água, carboidratos solúveis em éter (açúcares simples), carboidratos não fibrosos, fibra de detergente neutra, fibra de detergente ácido, lignina, amido, proteína bruta e gordura bruta. Os resultados foram submetidos a análise de variância e comparadas pelo teste $\mathrm{F}$, utilizando o programa estatístico SAS (2001), com nível de significância de 5\% (Quadro 1).

Avaliação da toxicidade de Panicum maximum cv. Massai para equinos em diferentes meses da estação chuvosa e análise bromatológica da pastagem. Cinco equinos foram utilizados para determinar a variação da toxicidade de $P$. maximum cv. Massai em uma propriedade rural localizada no município de Ji-Paraná, Rondônia, em uma pastagem onde haviam ocorrido casos de cólicas. Cada equino recebeu o pasto cortado em diferentes meses; o primeiro no mês de novembro e o último em março. 0 P. maximum var. Massai era fornecido aos animais, logo após o corte, no período da manhã, na dose de 20 quilos por dia, durante os três primeiros dias do mês. Uma amostra do capim oferecida aos animais foi enviada para o laboratório de Equi-Analytical- Laboratories para determinação dos parâmetros mencionados anteriormente (Quadro 2). Os equinos permaneciam numa pastagem de Brachiaria humidicula, e somente eram retirados para a administração do P. maximum. Durante os três dias de administração, os equinos eram observados visualmente e quando manifestava alterações clínicas o P. maximum era retirado e realizado exame físico do animal e iniciado o tratamento.

\section{RESULTADOS}

Levantamento epidemiológico dos casos de cólica em equídeos na microrregião da Amazônia Ocidental

Nas 10 propriedades visitadas, Panicum maximum cv. Massai foi responsável pela metade dos relatados de cólica, seguido de quatro surtos no cv. Tanzânia e um no cv. Mombaça. Dos 10 surtos estudados, dois ocorreram em novembro, um em janeiro, dois em fevereiro, quatro em março e um em abril. Em oito propriedades rurais as pastagens eram destinadas ao consumo dos bovinos e uma para terminação de ovinos. A entrada dos equídeos nas pastagens ocorria após a saída dos bovinos, embora a utilização destas estava condicionada à lotação animal ou a disponibilidade de volumoso. Quando havia baixa disponibilidade de forragem eram retirados os bovinos e os equinos eram colocados nas pastagens após um período de recuperação de 20 a 30 dias, quando a gramínea estava rebrotando. Em outra propriedade, que utilizava a var. Massai para a terminação de ovinos, os casos foram observados quando, no mês de março, foram introduzidos três equinos pertencentes a outra propriedade. De acordo com o produtor, os animais foram colocados na pastagem no final do dia e na manhã seguinte foram vistos com sinais de cólica. Nove propriedades praticavam sistemas extensivos: seis alimentavam os equídeos exclusivamente com volumoso e três suplementavam com concentrado em doses inferiores de $1.600 \mathrm{~g}$. A $10^{a}$ propriedade foi a única que apresentou casos de cólica em sistema intensivo; os casos foram observados após a troca da Brachiaria radicans pelo P. maximum cv. Mombaça, fornecido cortada aos animais, no mês de março. Os dados pluviométricos mensais se apresentam na Figura 1.

Os sinais clínicos eram observados após 12 a 96 horas da entrada dos equídeos nas pastagens, durante os meses chuvosos, de novembro a março. De um total de 114 equídeos, 36 apresentaram cólica $(31,58 \%)$ e 31 morreram $(86,1 \%)$ após um curso clínico de 6 a 48 horas. Os sinais clínicos eram caracterizados por sudorese excessiva,

Quadro 1. Análise bromatológica de Panicum maximum cv. Massai e cv. Tanzânia de duas propriedades onde ocorreram cólicas, de P. maximum cv. Tanzania de propriedades onde não ocorreram cólicas e de pastagens de capim Tifton onde haviam pastejado anteriormente os equinos experimentais

\begin{tabular}{|c|c|c|c|c|c|c|c|c|c|c|c|}
\hline $\begin{array}{l}\text { Variáveis } \\
\text { na Materia } \\
\text { verde }\end{array}$ & $\begin{array}{l}\text { P. Maximum } \\
\text { cv. Tanzania } \\
\text { Propriedade } \\
\text { monitorada }\end{array}$ & $\begin{array}{l}\text { P. Maximum } \\
\text { cv. Massai } \\
\text { Propriedade } \\
\text { monitorada }\end{array}$ & Média & $\begin{array}{l}\text { P. Maximum } \\
\text { cv. Tanzânia } \\
\text { Testemunha }\end{array}$ & $\begin{array}{l}\text { P. Maximum } \\
\text { cv. Tanzânia } \\
\text { Testemunha }\end{array}$ & Média & $\begin{array}{c}\text { Tifton } \\
\text { Testemunha }\end{array}$ & $\begin{array}{c}\text { Tifton } \\
\text { Testemunha }\end{array}$ & Média & $\begin{array}{l}\text { Coeficiente } \\
\text { de Variação }\end{array}$ & Probabilidade \\
\hline ED Mcal/kg & 1,82 & 1,77 & 1,79 & 1,60 & 1,76 & 1,68 & 1,68 & 1,69 & 1,68 & 2,78 & 0,1050 \\
\hline $\begin{array}{l}\text { Proteína } \\
\text { bruta }(\%)\end{array}$ & 8,8 & 9,9 & 9,35 & 6,5 & 13,3 & 9,9 & 15,7 & 16,7 & 16,2 & 34,09 & 0,4564 \\
\hline Lisina (\%) & 0,34 & 0,39 & 0,36 & 0,25 & 0,52 & 0,38 & 0,61 & 0,65 & 0,63 & 34,25 & 0,4568 \\
\hline Lignina (\%) & 3,9 & 4,6 & 4,25 & 4,8 & 3,9 & 4,35 & 2,3 & 3,5 & 2,9 & 27,97 & 0,8030 \\
\hline $\mathrm{ADF}(\%)$ & 35,1 & 34,8 & 34,95 & 40,6 & 33,6 & 37,1 & 30,1 & 31,0 & 30,5 & 12,91 & 0,7726 \\
\hline NDF (\%) & 58,8 & 52,4 & 55,60 & 62,1 & 53,1 & 57,6 & 53,9 & 57,0 & 55,05 & 8,06 & 0,8009 \\
\hline WSC (\%) & 4,5 & 8,2 & 6,35 & 6,7 & 8,2 & 7,45 & 10,0 & 5,8 & 7,9 & 31,08 & 0,6951 \\
\hline $\operatorname{ESC}(\%)$ & 2,6 & 3,5 & 3,05 & 5,9 & 5,3 & 5,6 & 3,5 & 2,9 & 3,2 & 36,29 & 0,5712 \\
\hline Amido (\%) & 8,3 & 9,2 & $8,75^{a}$ & 0,9 & 4,3 & $2,6 b$ & 0,2 & 0,8 & $0,5 c$ & 38,04 & 0,0247 \\
\hline NFC (\%) & 14,8 & 16,1 & 15,45 & 11,5 & 11,9 & 11,7 & 7,5 & 4,6 & 6,05 & 31,07 & 0,2294 \\
\hline Gordura & 1,9 & 1,8 & 1,85 & 1,5 & 2,2 & 1,85 & 2,0 & 2,6 & 2,3 & 13,22 & 0,1643 \\
\hline
\end{tabular}

bruta $(\%)$

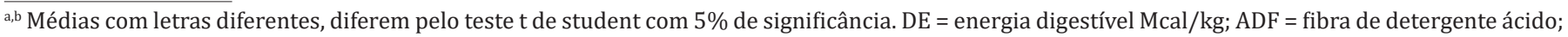
FDN = fibra de detergente neutro; WSC = carboidratos solúveis em água; ESC = carboidratos solúveis em éter (açúcares simples); CNF = carboidrato não fibrosos. 
Quadro 2. Análises bromatológicas de uma pastagem de Panicum maximum cv. Massai, cortado e administrado a equinos, mensalmente, durante a estação chuvosa. Das cinco coletas a única que induziu cólica foi a administrada no mês de março

\begin{tabular}{lccccc}
\hline \multirow{2}{*}{$\begin{array}{l}\text { Variável na } \\
\text { Matéria Verde }\end{array}$} & \multicolumn{5}{c}{ Mês de administração } \\
\cline { 2 - 6 } & Novembro & Dezembro & Janeiro & Fevereiro & Março \\
\hline DE Mcal/kg & 1,66 & 1,51 & 1,57 & 1,69 & 1,75 \\
Proteína Bruta (\%) & 13,2 & 13,7 & 10,6 & 12,4 & 8,5 \\
Lisina (\%) & 0,51 & 0,53 & 0,41 & 0,48 & 0,33 \\
Lignina (\%) & 5,6 & 6,3 & 4,7 & 2,2 & 3,8 \\
ADF (\%) & 33,1 & 33,9 & 36,9 & 33,8 & 38,0 \\
NDF (\%) & 54.4 & 56.6 & 56.3 & 58.2 & 58.0 \\
WSC (\%) & 6,2 & 4,7 & 7,6 & 8,8 & 9,4 \\
ESC (\%) & 4,1 & 4,7 & 3,1 & 2,8 & 5,1 \\
Amido (\%) & 4,9 & 2,7 & 5,0 & 5,1 & 6,5 \\
NFC (\%) & 9,0 & 4,7 & 9,5 & 9,8 & 14,7 \\
Gordura bruta (\%) & 2,1 & 1,9 & 1,7 & 1,4 & 1,7
\end{tabular}

$\overline{\mathrm{DE}}$ = energia digestível Mcal $/ \mathrm{kg} ; \mathrm{ADF}$ = fibra de detergente ácido; $\mathrm{FDN}=$ fibra de detergente neutro; WSC = carboidratos solúveis em água; ESC = carboidratos solúveis em éter (açúcares simples); CNF = carboidrato não fibrosos.

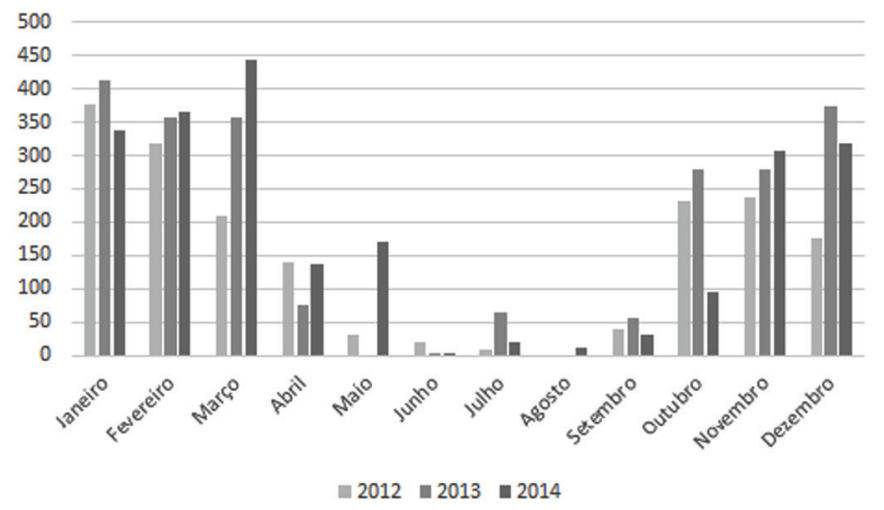

Fig. 1. Representação gráfica da pluviometria da região central de Rondônia durante o período de 2012 - 2014.

ausência de movimentos intestinais, anorexia, distensão abdominal, rolamento e fezes liquidas que ficavam ressecadas como o avanço do curso clínico. Na palpação retal eram observadas fezes secas, com distensão das alças intestinais e do ceco. Foram necropsiados seis equídeos que apresentaram quadro de cólica e morreram. Os achados macroscópicos observados foram distensão por gás das paredes do estômago, ceco, cólon maior e menor. Os pulmões, traqueia, faringe e fígado estavam congestos e a musculatura dos membros, tronco e pescoço apresentava áreas hemorrágicas. Em três equinos a porção glandular do estômago e a mucosa intestinal estavam hemorrágicas com conteúdo líquido de coloração marrom. Presença de conteúdo ressequido no ceco e na alça maior foram observados em quatro animais. 0 fígado de um equino apresentava hemorragias multifocais e áreas claras. Os produtores, também foram questionados quanto a utilização de algum tratamento anterior; somente uma propriedade tinha histórico de administração de vermífugo, dois dias antes, e três relataram que os casos ocorreram após os animais serem colocados no serviço. Os resultados das amostras de fezes, dos equídeos que morreram após a sín- drome de cólica apresentaram baixa quantidade de ovos por gramas fezes.

Análise bromatológica de pastagens de Panicum Maximum cv. Tanzânia e cv. Massai e alterações clínicas de equinos introduzidos nas mesmas

Em uma das propriedades, os dois equinos colocados na pastagem de P. maximum var. Massai, durante o mês de março apresentaram sinais clínicos. 0 Equino 1 apresentou sinais clínicos cinco horas após a entrada dos animais na pastagem e o Equino 2, três horas após a entrada. Os sinais eram caracterizados por parada dos movimentos intestinais, distensão das paredes do abdômen, rolamento, inquietação, sudorese e fezes líquidas. Os equinos foram retirados da pastagem logo após a observação dos sinais e realizado o tratamento com analgésicos, fluidoterapia, lavagem gástrica e tiflocentese. Em outra propriedade com relatos de cólica por P. maximum cv. Tanzânia foram colocados cinco equinos, no mesmo período do ensaio realizado no $P$. maximum cv Massai. Dois equinos apresentaram distensão abdominal leve oito horas após ao início do consumo da gramínea e se recuperaram após 12 horas da retirada da pastagem. A análise bromatológica das pastagens de P. maximum cv. Massai e cv. Tanzânia apresentou diferenças significativa para o amido $(\mathrm{P}=0,0072)$, quando comparado com o P. maximum das propriedades vizinhas que não tiveram cólicas (testemunhas) e com o Tifton, utilizado na alimentação dos equinos anteriormente. Já as demais variáveis não apresentaram diferenças significativas, usando um nível de significância de 5\%. (Quadro 1).

Avaliação da toxicidade de Panicum maximum cv. Massai para equinos em diferentes meses da estação chuvosa e análise bromatológica da pastagem

No cavalo que recebeu P. maximum cv. Massai durante o mês de março foram observados sinais clínicos da intoxicação cinco horas após a administração. Os mesmos eram caracterizados por parada dos movimentos intestinais, distensão das paredes do abdômen, rolamento, inquietação, sudorese e fezes ressequidas. Logo após a observação dos sinais foi retirada a gramínea e iniciado tratamento com analgésicos, fluidoterapia, lavagem gástrica e tiflocentese. 0 equino não respondeu ao tratamento e morreu após 24 horas, sendo realizada a necropsia. As principais lesões observadas foram distensão das paredes do estômago, ceco e cólon maior por gás, com áreas de hemorragia na mucosa, ruptura do cólon menor, peritonite e congestão pulmonar. Nos cavalos que receberam P. maximum var. Massai nos demais meses da estação chuvosa não foram observadas alterações clínicas. 0 exame bromatológico das pastagens durante os meses que durou o experimento se apresentam no Quadro2.

\section{DISCUSSÃO}

Em Rondônia, os surtos de cólica por timpanismo intestinal em equídeos foram observados quando os equinos entraram em pastagens de P. maximum cv. Massai, cv. Tanzânia e cv. Mombaça que estavam rebrotando, durante os meses de novembro a abril; no entanto, a doença foi mais 
frequente no mês de março. Com os dados epidemiológicos coletados durante o período das visitas as propriedades e exames físicos realizados nos equinos intoxicados foi possível estimar uma morbidade de $31,6 \%$ com uma letalidade de $86,1 \%$. Em um trabalho anterior realizado no estado do Pará a morbidade foi de 34\% e a letalidade de 36,5\% (Cerqueira et al. 2009).

Clinicamente, os episódios de cólica são caracterizados por distensão abdominal e dor aguda, com curso clínico de 6 a 48 horas. Nas necropsias dos equinos intoxicados, os achados macroscópicos eram caracterizados por distensão das paredes do estômago, ceco, cólon maior e cólon menor pelo acúmulo de gás. Alterações clínico/patológicas semelhantes a estas são descritas nos casos de timpanismo intestinal dos equinos, causado pela maior produção de gás ou sua retenção em segmentos intestinais (Archer \& Proudman 2006, Cerqueira et al. 2012). Além da intoxicação por P. maximum (Cerqueira et al. 2009, 2012), o timpanismo intestinal pode ser causado por mudança súbitas das dietas, hipocalcemia aguda, deslocamentos do cólon, compactação e consumo de grande quantidade de alimentos verdes fermentáveis; no entanto, na maioria dos casos é idiopática (Allen \& Tyler 1990, White 1990, Radostits et al. 2000).

Em duas propriedades nas que foram introduzidos equinos em pastagens de P. maximum, durante o mês de março, os animais adoeceram 3 e 5 horas após serem introduzidos na pastagem. 0 estudo bromatológico das gramíneas, coletadas antes da entrada dos animais, demostrou uma diferença significativa nas concentrações de amido $(\mathrm{P}=0,0072)$, quando comparado com as mesmas espécies de outras propriedades vizinhas, onde não estavam ocorrendo casos da intoxicação, e com as amostras de capim Tifton das pastagens utilizados pelos equinos antes da entrada no $P$. maximum (Quadro 1). 0 amido é um carboidrato digerido preferencialmente no interior do intestino delgado; quando ingerido em excesso, ocorre a fermentado no intestino grosso (Flis 2015). 0 excesso de amido no interior do ceco, causa alteração da microbiota cecal, favorecendo a proliferação de Lactobacillus, com aumento da produção de lactato, ácido láctico e gases. 0 excesso de gás expande as paredes do trato digestivo levando um quadro de dor no animal (Hoffman et al. 2003). Em trabalhos anteriores foi sugerido que a causa das cólicas causadas por $P$. maximum em cavalos era a maior concentração de carboidratos não fibrosos, possivelmente pela fração de carboidratos rapidamente fermentáveis, que são calculados pela diferença entre os carboidratos não fibrosos e os carboidratos hidrolisáveis e incluem fibra solúvel, oligossacarídeos, algumas fructanas e galactanas e amidos resistentes à hidrólise (Cerqueira 2010). No entanto, nesse trabalho os carboidratos haviam sido analisados com os métodos utilizados para bovinos que não permitem identificar algumas dessas frações de carboidratos importantes para a digestão dos equinos (Hoffman et al. 2003), enquanto que no trabalho aqui descrito foram analisados todos os carboidratos importantes para interpretar os distúrbios digestivos em equinos produzidos por estas substâncias. Na avaliação clínica e bromatológica da enfermidade, $P$. maximum cv Massai que causou a doença, no mês de março, embora tinha um aumento do amido em comparação com os outros meses do período chuvoso, este foi inferior ao observado em propriedades monitorados com episódio de cólica. Evidentemente que novos trabalhos deverão ser realizados para comprovar que as cólicas em equinos em pastagens de P. maximum são causados pelo excesso de amido nessas pastagens.

Na região Norte, no período chuvoso no que ocorrem os surtos de cólica, as precipitações pluviométricas estão acima de 230 milímetros/mês e as temperaturas médias são de 27 a $29^{\circ} \mathrm{C}$. Pesquisas com gramíneas e leguminosas de clima temperado e tropical demostraram variações sazonais no teor de carboidratos de armazenamento, associadas a diferentes necessidades de energia e fases de crescimento, com maiores concentrações em temperaturas quentes $\left(15-25^{\circ} \mathrm{C}\right)$ e menores nas temperaturas baixas (5$10^{\circ} \mathrm{C}$ ) (Waite \& Boyd 1953, Demarquilly et al. 1981). Além das variações sazonais, também ocorrem variações dentro de uma mesma pastagem na mesma época, como resultado de efeitos ambientais, tais como, intensidade de luz, temperatura, fertilizantes e quantidade de água disponível (Demarquilly et al. 1981). Temperaturas e níveis pluviométricos altos, como os observados na região Norte, criam ambiente singular em relação as outras regiões do Brasil. Estas condições climáticas, proporcionam nas gramíneas tropicais, fotossíntese que fixa o dióxido de carbono da atmosfera na forma de amido, diferente de gramíneas de clima temperado que acumulam frutanas como carboidratos de reservas (Chatterton et al. 1989). Concentrações de carboidratos de armazenamento, nos tecidos vegetais, estão mudando constantemente, em função da fotossíntese, crescimento e desenvolvimento. Isso resulta em variações diurnas no teor de carboidratos de armazenamento, bem como nas concentrações, que tendem a subir durante a manhã, atingir valores máximos durante a tarde, e cair durante a noite (Bowden et al. 1968, Longland \& Byrd 2006). Assim como a intensidade de luz, temperatura e quantidade de água disponível poderiam ser diferentes no momento das coletas das gramíneas, produzindo resultados diferentes (Demarquilly et al. 1981). A quantidade de água nas pastagens poderia, também, favorecer a ocorrência de cólicas, pois em condições ambientais favoráveis apresentam rápido crescimento, com altos teores de água (80\%), que não satisfazem os requisitos de matéria seca para os equinos, induzindo uma maior ingestão de volumoso (King 2000).

Em conclusão, em Rondônia, assim como em outros estados da região norte do Brasil, ocorrem cólicas por timpanismo intestinal em equídeos introduzidos recentemente em pastagens em brotação de $P$. maximum durante a época de chuvas. A maioria dos surtos ocorrem no mês de março quando as pastagens contêm altas concentrações de amido. São necessários mais trabalhos para determinar se as altas concentrações de amido são a causa da doença e quais são as condições ambientais ou do solo que determinam essas altas concentrações.

Agradecimentos.- Ao INCT para o Controle das Intoxicações por Plantas (Processo 573534/2008-0) e ao Conselho Nacional de Desenvolvimento Científico e Tecnológico (CNPQ) pelo apoio financeiro e ao Programa de pós-graduação Ciências Ambientais (PGCA). 


\section{REFERÊNCIAS}

Allen D. \& Tyler D. 1990. Pathophysiology of acute abdominal disease, p.6587. In: The Equine Acute Abdomen. Anais. Lea and Febiger, Philadelphia.

Archer D.C. \& Proudman C.J. 2006. Epidemiological clues to preventing colic. Vet. J. 172:29-39.

Bowden D.M., Taylor D.K. \& Davis W.E.P. 1968. Water-soluble carbohydrates in orchardgrass and mixed forages. Can. J. Plant Sci. 48:9-15.

Cerqueira V.D., Riet-CorreaI G., Duarte M.D., Oliveira C.A. \& Riet-Correa F. 2012. Bloat and colic in horses experimentally induced by the ingestion of Panicum maximum cv. Mombaça. Ciência Rural 42(11):2030-2033.

Cerqueira V.D.., Riet-Correa G., Barbosa J.D., Duarte M.D., Oliveira C.M., Tokarnia C.H., Lee S. \& Riet-Correa F. 2009. Colic caused by Panicum maximum toxicosis in equidae in northern Brazil. J. Vet. Diagn. Invest. 21:882-888

Cerqueira V.D. 2010. Cólica em equídeos mantidos em diferentes cultivares de Panicum maximum no bioma amazônico. Tese de Doutorado em Ciências, Faculdade de Medicina Veterinária e Zootecnia, Universidade de São Paulo, São Paulo. 90p.

Chatterton N.J., Harrison P.A., Bennett J.H. \& Asay K.H. 1989. Carbohydrate partitioning in 185 accessions of graminae grown under warm and cool temperatures. J. Plant Physiol. 1143:169-179.

Demarquilly C., Andrieu J. \& Wegat-Litre E. 1981. Prévision de la valeurnutritive des aliments des ruminants. INRA Institute National de la Recherche Agronomique, Versailles, Paris. 580p.

Flis S. 2015. How are sugar and starch, measured in hay feed and crop support specialist. Equi-Analytical Laboratories, Ithaca, NY. Disponível em <http://equi-analytical.com/wp-content/uploads/2015/11/Equi-Analytical_Newsletter_Fall_2015.pdf> Acesso em 5 nov. 2015.

Hoffman R.M., Boston R.C., Stefanovski D., Kronfeld DS. \& Harris P.A. 2003. Obesity and diet affect glucose dynamics and insulin sensitivity in thoroughbred geldings. J. Anim. Sci. Set. 81:2333-2342.
Jank L.A. 2003. História de Panicum maximum no Brasil. Jc Maschietto, Artemídia, Ago., 01(01):37-41.

King C. 2000. Preventing spring colic in horses: flying changes. Disponível em <http://www.flyingchanges.com/htmls/ 2000/mar00colic.html> Acesso em 2 nov. 2015

Longland A.C. \& Byrd B.M. 2006. Pasture nonstructural carbohydrates and equine laminitis. J. Nutr. 136(7):2099-2102.

Macedo M.C.M. 2005. Pastagens no ecossistema Cerrado: evolução das pesquisas para o desenvolvimento sustentável. 42ª Reunião da Sociedade Brasileira de Zootecnia, Anais dos Simpósios "Produçao Animal e Foco no Agronegócio", Goiânia, p.56-84.

Mari L.J. 2003. Intervalo entre cortes em capim-marandu (Brachiaria brizantha (Hochst. ex A. Rich) Stapf cv. Marandu: Produção, valor nutritivo e perdas associadas à fermentação da silagem. Dissertação de Mestrado, Esalq, Piracicaba, Universidade de São Paulo. 115p.

Martha Jr G.B. \& Corsi M. 2001. Pastagens no Brasil: situação atual e perspectivas. Preços Agrícolas, Piracicaba, 171:3-6.

Radostits O.M., Gay C.C., Blood D.C. \& Hinchcliff K.W. 2000. Clínica Veterinária: um tratado de doenças dos bovinos, ovinos, suínos, caprinos e equinos. 9a ed. Guanabara Koogan, Rio de Janeiro.

Riet-Correa B., Riet-Correa F., Simões S.V. \& Silva T.D. 2011. Alterações digestivas em bovinos mantidos em pastagem de Panicum maximum cultivar Tanzânia. Vet. Zootec. 18(3):633-635.

Schons S.V., Lopes T.V., Melo T.L., Lima J.P., Riet-Correa F., Barros M.A.B. \& Schild A.L.P. 2012. Intoxicações por plantas em ruminantes e equídeos na região central de Rondônia. Ciência Rural 42:1257-1263.

Waite R. \& Boyd J. 1953. The water-soluble carbohydrates in grasses: changes occurring during the normal life cycle. J. Sci. Food. Agric. 4:197220.

White N.A. 1990. Epidemiology and etiology of colic, p.49-64. In: White N.A. (Ed.), The Equine Acute Adomen. Lea and Febiger, Philadelphia,PA. 